\title{
Synthesis of Poly(methyl methacrylate) Microspheres Bearing Phosphatidylcholine Analogous and Azobenzene Moieties
}

\author{
Kazuo SugiYama, ${ }^{\dagger}$ Kohei Shiraishi, Koji Ohga, ${ }^{*}$ \\ Hiroyuki Shirahama, ${ }^{* *}$ Hisashi TamaI, ${ }^{* *}$ Kiyoshi KikuKawa, ${ }^{*}$ \\ and Hajime YASUDA** \\ Department of Industrial Chemistry, Faculty of Engineering, Kinki University, \\ Takaya, Higashihiroshima, Hiroshima 729-17, Japan \\ *Department of Advanced Materials, Graduate School of Advanced Technology, \\ Kinki University in Kyushu, Kashiwanomori, Iizuka, Fukuoka 820, Japan \\ **Department of Applied Chemistry, Faculty of Engineering, Hiroshima University, \\ Higashihiroshima 724, Japan
}

(Received November 16, 1992)

\begin{abstract}
Microsphere, poly(MAHP-co-MMA), was prepared by the emulsifier free emulsion copolymerization of 2-[2-(methacryloyloxy)ethyldimethylammonio]ethyl-6-[4-(4-methoxyphenylazo)phenoxy]hexyloxyphosphate (MAHP) and methyl methacrylate (MMA). The diameter of poly (MAHP-co-MMA) estimated from TEM varied from 234 to $402 \mathrm{~nm}$, depending on the mol- $\%$ of MAHP to MMA in feed from $f=0$ to $f=0.5$. From XPS measurements of poly (MAHP-co-MMA) the polar head groups of MAHP were found to be located on the surface of particles. The adsorption of bovine serum albumin (BSA) onto poly(methyl methacrylate) [poly(MMA)] and poly(MAHP-co-MMA) microspheres were examined at $\mathrm{pH}$ 5.6. The introduction of phosphatidylcholine analog into poly(MMA) results in a drastic decrease in BSA adsorption. A controlled decrease in BSA adsorption was also observed in poly(MAHP-co-MMA) with cis-azobenzene moieties caused by UV irradiation.

KEY WORDS Emulsion Polymerization / Microsphere / Phosphatidylcholine Analogous Monomer / Poly(methyl methacrylate) / Azobenzene Moieties / Albumin Adsorption / XPS /
\end{abstract}

Considerable attention has been paid to the design of biomedical materials towards improved thrombo-resistance. The blood compatibility was studied for the various materials, such as poly(vinyl chloride) including prostaglandin, modified poly(vinyl alcohol), and several polyurethanes. ${ }^{1-4}$ Incorporation of the zwitterionic head group of phosphatidylcholine into polymeric materials is also useful for the biomedical purposes. ${ }^{5-7}$ We and others have been interested in the polymers having phosphatidylcholine analogous moieties as pendant groups on the main chain ${ }^{8-18}$ and phosphatidylcholine moieties as blocks within the main chan. ${ }^{19-21}$

On the other hand, since a polymeric micro- sphere prepared through emulsion polymerization has great advantages such as extremely large surface area, highly uniform size, and controlled surface charge density, it is used as medical diagnostics, ${ }^{22}$ protein separators, ${ }^{23}$ carriers drug delivery system, ${ }^{24}$ and enzymeimmobilized materials ${ }^{25}$ other than industrial use. The effect of the surface characteristics of polymeric microspheres on the protein adsorption has also been studied using various polymer latices as adsorbents for albumin. ${ }^{26-29}$ In this connection our effort was directed toward the polymeric microspheres introducing both polar head group of phosphatidylcholine and azobenzene moieties as one of the basic courses for the development 
of biomedical materials. The present paper describes on the emulsion copolymerization of methyl methacrylate (MMA) and 2-[2-(methacryloyloxy)ethyldimethylammonio]-6-[4-(4methoxyphenylazo)pheroxy] hexyloxyphosphate (MAHP). Subsequently, the resulting polymeric microspheres, poly(MAHP-coMMA), were characterized, and the absorption behavior of bovine serum albumin (BSA) onto them was examined.

\section{EXPERIMENTAL}

\section{Materials}

MMA monomer was obtained from Wako Chemicals Inc. and was distilled under reduced pressure of nitrogen at $45^{\circ} \mathrm{C}$. MAHP was prepared in $85 \%$ yield by the reaction of 2-\{6-[4-(4-methoxyphenylazo)phenoxy]hexyloxy $\}$-2-oxo-1,3,2 $\lambda^{5}$-phospholane and 2-dimethylaminoethyl methacrylate in THF following the method described previously. ${ }^{15}$ Potassium persulfate (KPS) was recrystallized from water. Crystallized and lyophilized BSA was obtained from Sigma Chemical Co. and was used without further purification. Distilled and deionized water was used throughout the experiments.

\section{Preparation of Polymer Microspheres}

Homo poly(MMA) and poly(MAHP-coMMA) were prepared by emulsifier free emulsion polymerization: into a $0.5 \mathrm{dm}^{3}$ separable round bottomed flask, equipped with a mechanical stirrer, condenser, $\mathrm{N}_{2}$ inlet tube, were placed a known amount of MMA and MAHP in water. After being kept at $70^{\circ} \mathrm{C}$ over a period of $1 \mathrm{~h}$, the required amount of KPS aqueous solution was added at once and the mixture was stirred for another $5 \mathrm{~h}$. For kinetics, an aliquot of emulsion sample obtained after polymerization for a given time was poured into a large amount of methanol to precipitate the polymer. The conversion was calculated from the weight of dry polymer obtained. For adsorption experiments, the polymeric microspheres were purified as follows. The polymeric microspheres obtained were filtrated through glass filter (1G4) to remove coarse particles and coagulated polymer. The aggregate was filtered, dried, and weighed. The filtrate was centrifuged, decanted, and redispersed in water. After repeating this procedure three times, polymeric microspheres were finally purified by treatment with mixed ion-exchange resins of cation- and anionexchange resins (PK-212 and PA-312) obtained from Mitsubishi Chemical Industries, Ltd.

\section{Adsorption Procedure}

The experiments for the adsorption of BSA onto poly(MMA) and poly(MAHP-co-MMA) were carried out at $25^{\circ} \mathrm{C}$ according to the method mentioned by Shirahama et al. ${ }^{26-29}$

\section{Measurements}

Gel permeation chromatographic (GPC) analysis was conducted in THF solution with TSK gel $\mathrm{G}(6+5+4+3+2) \mathrm{H}_{\mathrm{XL}}$, using a TOSOH SC-8010 GPC apparatus. The particle size of polymeric microspheres was determined by transmission electron microscopy (TEM) with a Topcon EM002B, and the size distribution of particle was measured with a Pacific Scientific NICOMP-370. The surface of the particle was analyzed by X-ray photoelectron spectroscopy (XPS) using a Simadzu ESCA 750. Trans-cis isomerization of sample was carried out as follows: a known amount of sample in THF was placed in a quartz tube

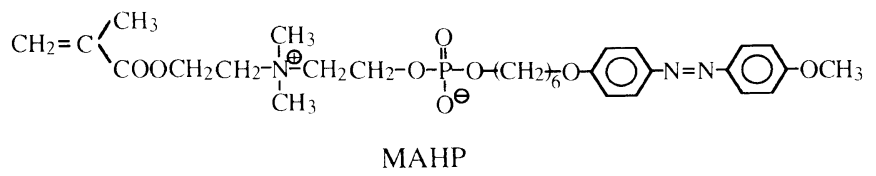

Scheme 1. 
placed on a merry-go-round Rayonet photochemical reactor Model-RMA-400 equipped with a 2RPR-253.7 nm lamp. The distance between tube and the lamps was $20 \mathrm{~cm}$. After irradiation for a given time, an aliquot of THF solution was submitted to UV measurements. The UV measurements were carried out with a Shimadzu UV-160A spectrophotometer.

\section{RESULTS AND DISCUSSION}

\section{Preparation of Poly(MAHP-co-MMA)}

Poly(MAHP-co-MMA) was prepared by the batch emulsion copolymerization of MAHP and MMA initiated by KPS in the absence of emulsifiers under a nitrogen atmosphere, varying the mol- $\%$ of MAHP to MMA monomer in feed from $f=0$ to $f=0.5$. An amphiphilic MAHP shows the phase transition from micelles to lyotropic liquid-crystal in aqueous solution as mentioned previously. ${ }^{13}$

Table I. Recipe for the emulsion copolymerization of MMA and MAHP

\begin{tabular}{ll}
\hline MMA & $300 \mathrm{mmol}$ \\
MAHP & $0-1.5 \mathrm{mmol}$ \\
KPS & $0.3 \mathrm{mmol}$ \\
Water & $0.3 \mathrm{dm}^{3}$ \\
Speed of agitation & $350 \mathrm{rpm}$ \\
Temperature & $70^{\circ} \mathrm{C}$ \\
Time & $5 \mathrm{~h}$ \\
\hline
\end{tabular}

The Krafft point and CMC were also found to be $34.7^{\circ} \mathrm{C}$ and $1.50 \times 10^{-4} \mathrm{~mol} \mathrm{dm}{ }^{-3}$, respectively. MAHP, then, acts as an emulsifier in this polymerization. The polymerization recipe is

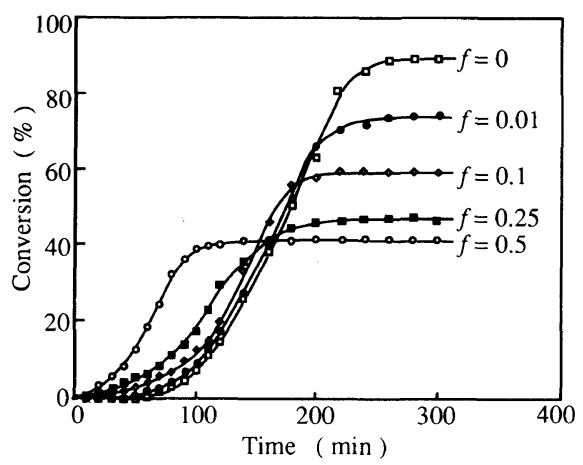

Figure 1. Conversion-time curves for the copolymerization of MAHP and MMA in $\mathrm{H}_{2} \mathrm{O}$ at $70^{\circ} \mathrm{C}$. $f$ represents the mol- $\%$ of MAHP to MMA monomer.

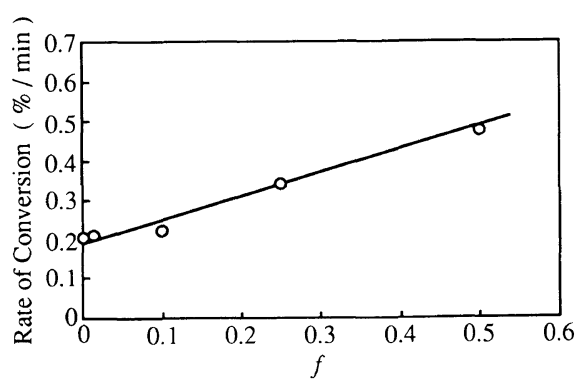

Figure 2. Effect of MAHP concentration on the initial rate of conversion of poly(MAHP-co-MMA) in the copolymerizaton of MAHP and MMA. $f$ represents the mol- $\%$ of MAHP to MMA monomer.

Table II. Results for the copolymerization of MMA and MAHP

\begin{tabular}{|c|c|c|c|c|c|c|c|}
\hline \multirow{2}{*}{ Run } & \multirow{2}{*}{$f^{\mathrm{b}}$} & \multirow{2}{*}{$\frac{\text { Microsphere }}{\%}$} & \multirow{2}{*}{$\frac{\text { Aggregates }^{c}}{\%}$} & \multirow{2}{*}{$\frac{\text { Diameter }^{\mathbf{d}}}{\mathrm{nm}}$} & \multicolumn{3}{|c|}{ Molecular weight ${ }^{\mathrm{e}}$} \\
\hline & & & & & $M_{n} \times 10^{-5}$ & $M_{w} \times 10^{-5}$ & $M_{w} / M_{n}$ \\
\hline 1 & 0 & 91.0 & 0.31 & $380 \pm 8$ & 1.87 & 9.06 & 4.83 \\
\hline 2 & 0.01 & 74.9 & 1.34 & $234 \pm 6$ & 1.85 & 7.96 & 4.29 \\
\hline 3 & 0.1 & 61.4 & 9.52 & $270 \pm 10$ & 2.03 & 8.98 & 4.41 \\
\hline 4 & 0.25 & 43.7 & 25.49 & $376 \pm 35$ & 1.62 & 7.05 & 4.36 \\
\hline 5 & 0.5 & 41.5 & 33.91 & $402 \pm 42$ & 2.44 & 11.31 & 4.64 \\
\hline
\end{tabular}

a Polymerization for $5 \mathrm{~h}$.

b $f$ represents the mol- $\%$ of MAHP to MMA monomer in feed.

c The aggregates were isolated from reaction mixture by filtration.

d Calculated from TEM.

e Determined by GPC compared to poly(MMA) standard in THF with TSK gel $\mathrm{G}(6+5+4+3+2) \mathrm{H}_{\mathbf{X L}}$. 
given in Table I. For kinetics, poly(MAHPco-MMA) emulsion was sampled from the stirred flask at various times. From the conversion-time curves for the polymerization (Figure 1), it was found that the addition of small amounts of MAHP was found to result in a decrease in an induction period and an increase in the polymerization rate within an earlier stage. The initial rate of polymerization increased linearly with increasing MAHP concentration as shown in Figure 2. This means that a large number of particles are produced when MAHP comonomer presents. ${ }^{30}$ On the other hand, a decrease of microsphere yield and an increase of aggregates at final stage was observed with increasing $f$ value in feed. It is well known that the hydrophile-lipophile balance (HLB) of the surfactants is important for the formation of microspheres in the emulsion polymerization. Since MAHP might be not enough hydrophilic to stabilize the growing particles, the microspheres resulted in the formation of aggregates. ${ }^{31}$ The results of copolymerization of MMA and MAHP for $5 \mathrm{~h}$ are summarized in Table II.

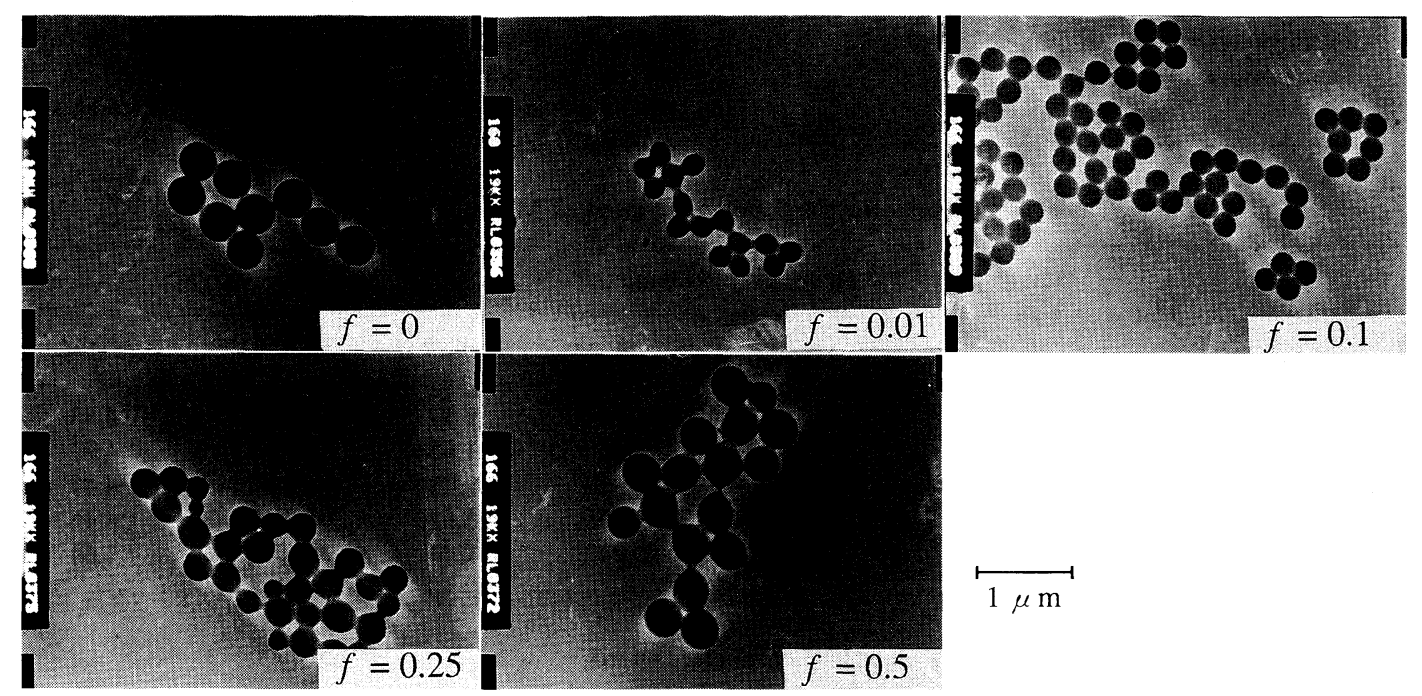

Figure 4. TEM micrographs of poly(MMA) and poly(MAHP-co-MMA). $f$ represents the mol- $\%$ of MAHP based on MMA monomer. $\times 19000$

\section{Particle Size}

Particle size measurements of poly(MAHPco-MMA) microsphere with $f=0.5$, depicted in Figure 3, show that the particle size increased

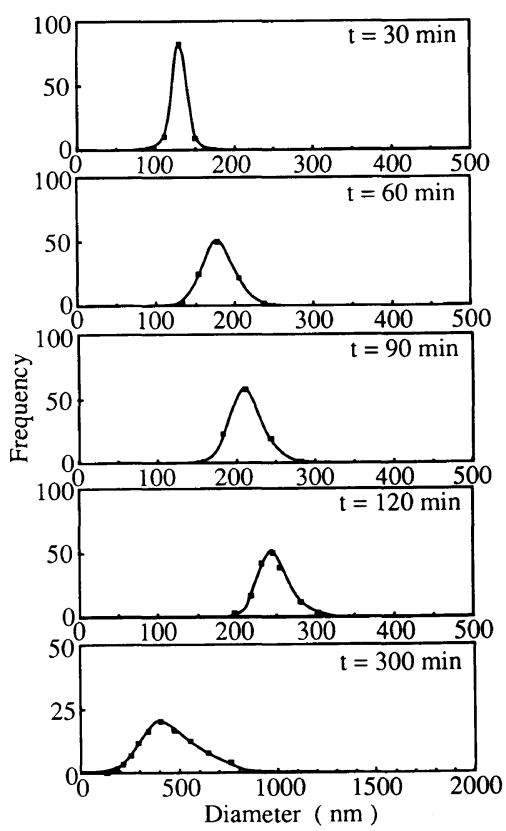

Figure 3. Particle size distribution for poly(MAHP-coMMA) (run 3 in Table II) as a function of polymerization time. 
as a function of polymerization time. TEM pictures of the final polymeric microspheres are shown in Figure 4. The diameter of poly(MAHP-co-MMA) estimated from TEM profiles is listed in Table II. The diameter of poly (MAHP-co-MMA) was varied from 234 to $402 \mathrm{~nm}$, depending on the content of MAHP. The particle size becomes larger in the case of $f=0.1$ or above, while the smallest particle size was found in case of $f=0.01$ case. In case of $f=0.1$ or above, the oligomeric radicals collide with MAHP micelles including MMA monomer, and this may be resulted in larger particle size.

On the other hand, a large number of stable charged oligomeric radicals containing MMA and MAHP will be formed when the concentration of MAHP is less than its CMC $(f=0.01)$ and the oligoradicals are converted into primary growing particles.

\section{Characterization of Surface}

The content of MAHP in poly(MAHP-coMMA) was determined by UV measurements of the absorbance at $357.5 \mathrm{~nm}$ based on azobenzene chromophore in THF solution. The concentration of MAHP in copolymer is in agreement with that of concentration in feed in every case as shown in Table III. XPS measurements were also carried out on poly(MAHP-co-MMA). The signals of $\mathrm{N}_{1 \mathrm{~s}}$ and $P_{2 p}$ are illustrated in Figure 5. The ratios of the number of atoms for phosphorus and nitrogen to carbon $(\mathrm{P} / \mathrm{C}$ and $\mathrm{N} / \mathrm{C})$ of poly(MAHP-co-MMA) before and after etching for $5 \mathrm{~min}$, are presented in Table II. Both values $\mathrm{P} / \mathrm{C}$ and $\mathrm{N} / \mathrm{C}$ of samples before etching were larger than those of etching ones. From the results in Table III, the polar head group of MAHP was found to be concentrated on the surface of poly(MAHP-co-MMA). The microspheres of which surface have an analogous structure to biomembrane could be utilized in various biomedical uses. ${ }^{20,21}$

BSA Adsorption onto Poly(MAHP-co-MMA)

The adsorption of BSA onto poly(MAHP-coMMA) was examined in water at $\mathrm{pH} 5.6$, varying ionic strength adjusted with $\mathrm{NaCl}$ aqueous solution, together with the adsorption experiment for poly(MMA) as a control. This $\mathrm{pH}$ value is close to the isoelectric point of BSA, of which molecules form compact structures. ${ }^{32}$ Figures 6 and 7 show the effect of ionic strength on the BSA adsorption onto poly(MMA) as a control and poly(MAHP-co-MMA), respec-

Table III. The content of MAHP in poly(MAHP-co-MMA)

\begin{tabular}{|c|c|c|c|c|}
\hline \multirow[t]{2}{*}{ Run } & \multirow{2}{*}{$f^{\mathrm{a}}$} & \multirow{2}{*}{$\begin{array}{c}\begin{array}{c}\text { MAHP in } \\
\text { particle }\end{array} \\
\%\end{array}$} & \multicolumn{2}{|c|}{ XPS analysis $^{c}$} \\
\hline & & & $10^{3} \mathrm{P} / \mathrm{C}$ & $10^{3} \mathrm{~N} / \mathrm{C}$ \\
\hline 1 & 0 & 0 & - & - \\
\hline 2 & 0.01 & 0.01 & - & - \\
\hline 3 & 0.1 & 0.12 & $1.44(0.33)$ & $1.44(0.77)$ \\
\hline 4 & 0.25 & 0.25 & - & - \\
\hline 5 & 0.5 & 0.49 & - & - \\
\hline
\end{tabular}

a $f$ represents the mol- $\%$ of MAHP to MMA monomer in feed.

b Calculated from the UV method using $\lambda_{\max } 357.5 \mathrm{~nm}$ of Azobenzene moieties in THF.

c $\mathrm{P} / \mathrm{C}$ and $\mathrm{N} / \mathrm{C}$ are the ratio of number of atom for $\mathrm{P}$ and $\mathrm{N}$ to $\mathrm{C}$. The value in bracket is obtained from the sample after etching for $5 \mathrm{~min}$.

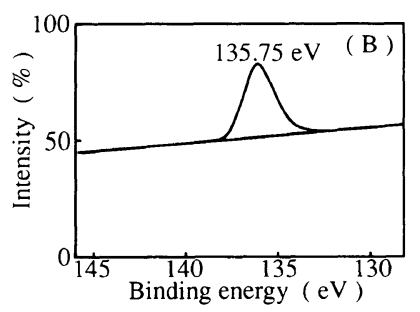

Figure 5. XPS for $\mathrm{N}_{1 \mathrm{~s}}$ (A) and $\mathrm{P}_{2 \mathrm{p}}$ (B) spectra of poly(MAHP-co-MMA) (run 3 in Table II). 


\section{K. SugiYama et al.}

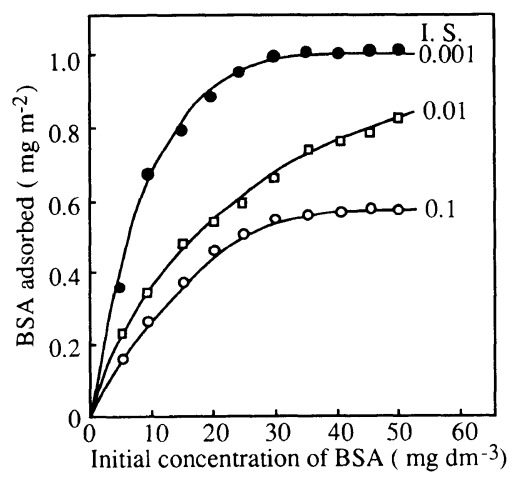

Figure 6. Amount of adsorbed BSA onto poly(MMA) (run 1 in Table II), $25^{\circ} \mathrm{C}$, pH 5.6. Ionic strength (I.S.) was varied.

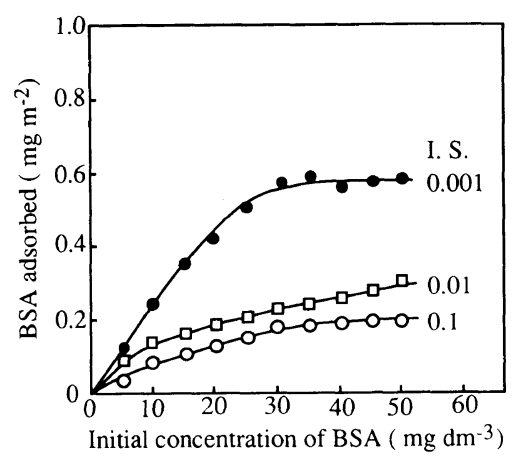

Figure 7. Amount of adsorbed BSA onto poly(MAHPco-MMA)(run 5 in Table II), $25^{\circ} \mathrm{C}, \mathrm{pH}$ 5.6. Ionic strength (I.S.) was varied.

tively. Increase in ionic strength resulted in a decrease in amount of BSA adsorbed onto poly(MMA) and poly(MAHP-co-MMA). This result shows the same tendency as in the case of poly(styrene) and poly(styrene/2-hydroxyethyl methacrylate) copolymer microspheres described by Shirahama. ${ }^{26}$ There are two factors that influence the adsorption of BSA onto the surface: electrostatic repulsion and hydrophobic interaction between BSA molecule and the particle. At present, it is not known which factor is dominant one. Comparing poly(MAHP-co-MMA) with poly(MMA), it is clearly said that the introduction of phosphatidylcholine analogs into poly (MMA) results in a drastic decrease in BSA adsorption.

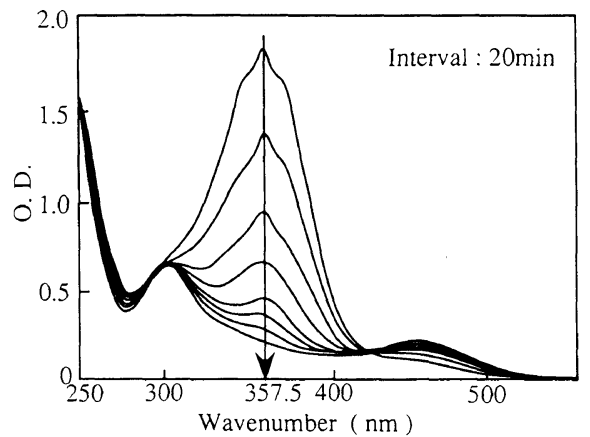

Figure 8. Spectral change of poly(MAHP-co-MMA) (run 5 in Table II) in THF at room temperature. The initial concentration of poly (MAHP-co-MMA) is $0.1 \mathrm{~g} \mathrm{dm}^{-3}$.

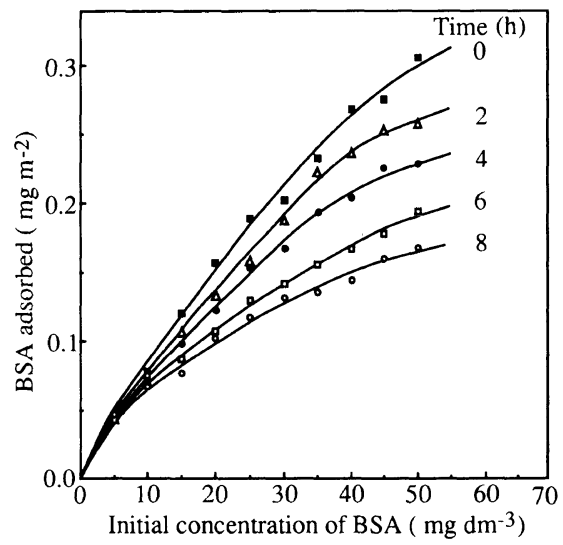

Figure 9. Amount of adsorbed BSA onto poly(MAHPco-MMA) (run 5 in Table II) after UV irradiation for a given time, $25^{\circ} \mathrm{C}$, pH 5.6. Ionic strength, 0.01 .

This could be explained by the electrostatic repulsion acting between BSA molecule and the particle, though $\xi$-potentials of poly(MAHP-co-MMA) were not measured yet. ${ }^{29}$ The change of configuration of azobenzene chromophore on poly(MAHP-co-MMA) was photochemically studied in order to obtain an information if the adsorbability of BSA onto the microspheres can be controlled by a trans-cis photoisomerization. Figure 8 shows the progressive spectral change of poly(MAHP-co-MMA) on irradiation with light of $253.7 \mathrm{~nm}$ in THF solution at room temperature. The rate of isomerization upon UV irradiation was found to be $3.15 \times 10^{-4} \mathrm{~s}^{-1}$. 
Figure 9 shows the adsorption of BSA onto the microspheres with cis-azobenzene, of which samples prepared by the UV irradiation on poly(MAHP-co-MMA) in water for a given time. In this case, the azobenzene moieties located on the surface of particles are considered to photoisomerize from trans-to cis-form. A controlled decrease in the amount of BSA adsorbed was observed with increasing the UV irradiation time. An increase in polarity of azobenzene moieties caused by photoisomerization from trans- to cis- form seems to be the reason for the decrease in BSA adsorption onto poly (MAHP-co-MMA). This is believed to be the first representative that the BSA adsorption can be controlled by a trans-cis photoisomerization being responsible for UV irradiation.

Acknowledgements. The authors thank Dr. T. Ohashi of Western Industrial Research Institute of Hiroshima for the measurements of XPS. Thanks are also due to Mr. T. Yoshida of Nippon Oil \& Fats Co., Ltd. of Tsukuba Research Laboratory for the measurements of particle size distribution. The authors are grateful to the Environmental Science Institute of Kinki University for financial support. This study was also supported by Grant-inAid for Science Research from Japan Private School Promotion Foundation.

\section{REFERENCES}

1. D. J. Lyman, K. Knutson, B. McNeill, and K. Shibatani, Trans. Am. Soc. Artif. Int. Organs. XX1, 49 (1975).

2. S. W. Kim, C. D. Ebert, J. Y. Lin, and J. C. MeRea, Asaio J., 6, 76 (1983).

3. Y. Ikeda, S. Kohjiya, S. Yamashita, H. Fukumura, and S. Yoshikawa, Polym. J., 20, 273 (1988).

4. J. Mathew and M. Kodama, Polym. J., 24, 31 (1992).

5. K. Ishihara, N. P. Ziats, B. P. Tierney, N. Nakabayashi, and J. M. Anderson, J. Biomed. Mater. Res., 25, 1397 (1991).

6. A. A. Durrami, J. A. Hayward, and D. Chapman, Biomaterials, 7, 121 (1986).
7. D. Letourneur, C. Douzon, and M. Jozefowicz. $J$. Polym. Sci., A, Polym. Chem., 29, 1367 (1991).

8. S. L. Regen, A. Singh, G. Oehme, and M. Singh, $J$. Amer. Chem. Soc., 104, 791 (1982).

9. H. Nishide and E. Tsuchida, Makromol. Chem., Rapid Commun., 5, 779 (1984).

10. M. Yasuzawa, T. Nakaya, and M. Imoto, $J$. Macromol. Sci., Chem., A23, 963 (1986).

11. H. Ohno, Y. Ogata, and E. Tsuchida, Macromolecules, 20, 929 (1987).

12. A. Furukawa, H. Shoji, T. Nakaya, and M. Imoto, Makromol. Chem., 188, 265 (1987).

13. Y. Ohkatsu, M. Yokota, and T. Kusano, Makromol. Chem., 189, 755 (1988).

14. K. Yamaguchi, S. Watanabe, and S. Nakahama, Makromol. Chem., 190, 1195 (1989).

15. K. Sugiyama and K. Shiraishi, Makromol. Chem., 190, 2381 (1989).

16. T. Nakaya, H. Kurio, M. Imoto, and K. Sugiyama, Polym. J., 21, 929 (1989).

17. T. D. Sells and D. F. O'Brien, Macromolecules, 24, 336 (1991).

18. K. Sugimaya and K. Shiraishi, Chem. Express, 7, 261 (1992).

19. T. Umeda, T. Nakaya, and M. Imoto, Makromol. Chem. Rapid Commun., 6, 287 (1985).

20. K. Sugiyama and T. Nakaya, Nippon Kagaku Kaishi, 1985, 2335 (1985); Chem. Abstr., 106, 214028W (1987).

21. K. Sugiyama and T. Nakaya, Makromol. Chem., Rapid Commun., 7, 679 (1986).

22. J. L. Robbins, G. A. Hill, B. N. Carle, J. H. Carlquist, and S. Marcus, Proc. Soc. Exp. Biol. Med., 109, 321 (1962).

23. A. Rembaum, S. P. S. Yen, and R. S. Molday, $J$. Macromol. Sci., Chem., A13, 603 (1979).

24. T. Ueda, K. Ishihara, and N. Nakabayashi, Makromol. Chem., Rapid Commun., 11, 345 (1990).

25. H. Kawaguchi, N. Koiwai, and Y. Ohthuka, J. Appl. Polym. Sci., 35, 743 (1988).

26. H. Shirahama and T. Suzawa, J. Colloid Interface Sci., 104, 416 (1985).

27. H. Shirahama and T. Suzawa, J. Colloid Interface Sci., 126, 269 (1988).

28. H. Shirahama, T. Suzuki, and T. Suzawa, J. Colloid Interface Sci., 129, 483 (1989).

29. H. Shirahama, H. Ohno, and T. Suzawa, Colloids and Surfaces, 60, 1 (1991).

30. J. H. Kim, M. Chainey, M. S. El-Aasser, and J. W. Vanderhoff, J. Polym. Sci., A, Polym. Chem., 30, 171 (1992).

31. K. Yamagichi, S. Watanabe, and S. Nakahama, Makromol. Chem., 190, 1195 (1989).

32. T. Suzawa, H. Shirahama, and T. Fujimoto, J. Colloid Interface Sci., 86, 144 (1982). 